\title{
Spatio-temporal analysis of the geographical centroids for three major crops in China from 1949 to 2014
}

\author{
FAN Lingling ${ }^{1}$, LIANG Shefang ${ }^{1}$, CHEN Hao ${ }^{1}$, HU Yanan ${ }^{2}$, ZHANG Xiaofei $^{3}$, \\ LIU Zhenhuan ${ }^{4}$, WU Wenbin ${ }^{1,5}$, 'YANG Peng ${ }^{1,5}$
}

1. Key Laboratory of Agricultural Remote Sensing (AGRIRS), Ministry of Agriculture/lnstitute of Agricultural Resources and Regional Planning, Chinese Academy of Agricultural Sciences, Beijing 100081, China;

2. Agricultural Information Institute, Chinese Academy of Agricultural Sciences, Beijing 100081, China;

3. Laboratory for Earth Surface Processes, Ministry of Education, College of Urban and Environmental Sciences, Peking University, Beijing 100871, China;

4. Department of Land Resources and Environment Studies, School of Geography and Planning, Sun Yat-Sen University, Guangzhou, 510275, China;

5. Chinese Academy of Agricultural Sciences-Ghent University Joint Laboratory of Global Change and Food Security, Beijing 100081, China

\begin{abstract}
Spatial distribution changes in major crops can reveal important information about cropping systems. Here, a new centroid method that applies physics and mathematics to spatial pattern analysis in agriculture is proposed to quantitatively describe the historical centroids of rice, maize and wheat in China from 1949 to 2014. The geographical centroids of the rice area moved $413.39 \mathrm{~km}$ in a $34.32^{\circ}$ northeasterly (latitude $3.08^{\circ} \mathrm{N}$, longitude $2.10^{\circ} \mathrm{E}$ ) direction at a speed of $6.36 \mathrm{~km} /$ year from central Hunan province to Hubei province, while the geographical centroids of rice production moved $509.26 \mathrm{~km}$ in the direction of $45.44^{\circ}$ northeasterly (latitude $3.22^{\circ} \mathrm{N}$, longitude $3.27^{\circ} \mathrm{E}$ ) at a speed of $7.83 \mathrm{~km} /$ year from central Hunan province to Henan province. The geographical centroids of the maize area and production moved $307.15 \mathrm{~km}$ in the direction of $34.33^{\circ}$ northeasterly (latitude $2.29^{\circ} \mathrm{N}$, longitude $1.56^{\circ} \mathrm{E}$ ) and $308.16 \mathrm{~km}$ in the direction of $30.79^{\circ}$ northeasterly (latitude $2.39^{\circ} \mathrm{N}$, longitude $1.42^{\circ} \mathrm{E}$ ), respectively. However, the geographical centroids of the wheat area and production were randomly distributed along the border of Shanxi and Henan provinces. We divided the wheat into spring wheat and winter wheat and found that the geographical centroids of the spring wheat area and production were distributed within Inner Mongolia, while the geographical centroids of winter wheat were distributed in Shanxi and Henan provinces. We found that the hotspots of crop cultivation area and production do not always change concordantly at a lar-
\end{abstract}

Received: 2017-03-14 Accepted: 2017-09-18

Foundation: National Key Research and Development Program of China, No.2017YFD0300201; National Natural Science Foundation of China, No.41401116; Ministry of Finance of China through the Non-Profit National Research Institute, No.Y2017JC30; Field Strategic Research Project of Medium and Long-Term Development Strategy of China's Engineering Science and Technology, No.2016-ZCQ-08

Author: Fan Lingling (1993-), Master Student, specialized in impact of climate change on agriculture.

E-mail: fanlingling@caas.cn

"Corresponding author: Yang Peng (1975-), Professor, specialized in global change and food security. E-mail: yangpeng@caas.cn 
ger, regional scale, suggesting that the changing amplitude and rate of each crops' yield differ between different regions in China. Thus, relevant adaptation measures should be taken at a regional level to prevent production damage in those with increasing area but decreasing production.

Keywords: geographical centroid; rice; maize; wheat; China

\section{Introduction}

The rapid growth of China's population has led to an increased demand for food which has been unfortunately accompanied by frequent food security problems in agricultural areas (Carter et al., 2003; Nelson et al., 2010; Ding et al., 2015). China is the largest producer and consumer of grain, placing it in an important position in global agricultural production. Even small changes in agricultural production system have a huge impact on Chinese food security with its increasing population and limited arable land (Ding et al., 2015; Li et al., 2015; He et al., 2017). The spatial and temporal distributions of Chinese crops are thought to reflect dynamic natural and anthropogenic external forces (You et al., 2009; Liu et al., 2013; Tan et al., 2014). Crop land use is closely related to changes in the crop planting area and production, which have increasingly been the focus of scientific research in recent years (Nelson et al., 2010; Kuemmerle et al., 2013; Cohn et al., 2016; Xia et al., 2016). Crop planting area and production, the most intuitive two indicators that could represent the productivity change of crops, are the results of selective planting due to systemic factors in internal agricultural production and external driving factors. Developing science and technology, increasing production input and the transforming concept of crop production in farmers have significant impacts on the crop distribution extension and location region. These factors reflect the importance of a crop in a given region, allowing national departments to put forward agricultural decision-making measures for key regions (You et al., 2009; Cui et al., 2014). Therefore, understanding how the spatial pattern of the crop planting area and production have historically changed will provide significant insights for predicting possible fluctuations in the agricultural production system (Verburg et al., 2013; Zhao et al., 2013; Deb et al., 2015; Szumigalski et al., 2016; Zheng et al., 2017).

Most research on crop spatial distribution changes has focused on the regional spatial change in crop area and production or the dynamics of the northern boundary of crops in China (Li et al., 2013; Tan et al., 2014; Iizumi et al., 2015; Yin et al., 2016). Liu et al. (2013) utilized the SPAM-China model to get a series of spatial distributions for rice area and production at $10-\mathrm{km}$ pixels at national scale from the early 1980 s onward and analyzed the pattern of spatial and temporal changes in China. Taking Binxian county of Heilongjiang province in China as an example, Zhang et al. (2013) analyzed the spatial and temporal variation characteristics of crop planting structure from 1996 to 2010. Results showed that the crop pattern exhibited a significant spatio-temperal change in the past 15 years, with an increase in crop planting area of $22.86 \%$. Li et al. (2012) analyzed the northern boundary of wheat and the potential planting distribution in China under the background of climate warming. He pointed out that the planting boundary of winter wheat moved to the north significantly at a rate greater than that of southern boundary due to the increasing temperature of China's winter over the past 30 years. However, few studies have investigated the geographical movements of crop planting area and production, which can provide a visualized under- 
standing of the migration of major crop regions. Some studies have analyzed the spatial changes based on the geographical centroid model, but they have not compared the cultivation centroids between varieties of main crops (Li et al., 2015; Liu et al., 2015). Therefore, understanding how the geographical centroids of major crop planting area and production have moved, both in terms of their size and geographic location, has significant implications for food security and production system management (Li et al., 2014; Wu et al., 2014).

Crop planting hotspots and expansion direction are subject to spatial heterogeneity (in terms of soil, terrain and climate), of which knowledge is of important for national resource allocation and a balanced market economy (You et al., 2006). Geographical movements in the crop planting area and production could impact or be affected by changing agronomic practices, local environmental conditions and the distribution system of the economic market (Wu et al., 2014; Li et al., 2015). However, the long-term quantitative changes in the distance and direction of external forces and their effects on the geographical centroids remain unclear, and a contrastive analysis of major Chinese crop production systems is needed.

The aim of this study is to fill this research gap by using a centroid calculation model derived from physics to acquire the geographical centroids of the planting area and production of three major crops in China from 1949 to 2014, specifically, rice, maize and wheat. During this process, we divided the wheat into winter wheat and spring wheat so that we could better analyse the specific characteristics within each major planting area. We then compare the changes in geographical centroids between the three crops and discuss the differences between the migratory routes of each crop's planting area and production. Using a long-term data series from 1949 to 2014, these results highlight the dynamic changes in the geographical centroids for the three major crops and the spatial movement of the important crop planting areas in China.

\section{Data source and methodology}

\subsection{Data sources}

We collected historical data for the three major crop areas and production for the 1949-2014 period from 31 provinces in China. These data were obtained from the Planting Information Network of China (http://zzys.agri.gov.cn/nongqing.aspx). The major Chinese crop areas and production in 2014 are shown in Table 1.

\subsection{Calculating geographical centroids}

The centre of gravity concept originates from physics, and now represents an important analytical tool for studying the spatial changes of factors in regional development processes. Additionally, regional development involves various factors that are in agglomeration and diffusion, and the movement of these factor centres show the spatial pathway of regional development. The production centroid model is a typical analysis model in the field of geography. We built a crop centroid method using the theory of gravity model to calculate the geographical centroids for the area and production of three major crops (unless otherwise indicated, the use of the term "wheat" represents the total wheat). This model addresses the dynamics of the centroids during the examined period and estimates the location (longitude, $X_{t}$ and latitude, $Y_{t}$ ) of the centroids for the three crop areas and productions. 
Table 1 The area and production of three major Chinese crops in 2014

\begin{tabular}{|c|c|c|c|c|c|c|}
\hline \multirow[b]{2}{*}{ Province } & \multicolumn{2}{|c|}{ Wheat } & \multicolumn{2}{|c|}{ Rice } & \multicolumn{2}{|c|}{ Maize } \\
\hline & $\begin{array}{c}\text { Area } \\
\text { (million ha) }\end{array}$ & $\begin{array}{l}\text { Production } \\
\text { (million tons) }\end{array}$ & $\begin{array}{c}\text { Area } \\
\text { (million ha) }\end{array}$ & $\begin{array}{l}\text { Production } \\
\text { (million tons) }\end{array}$ & $\begin{array}{c}\text { Area } \\
\text { (million ha) }\end{array}$ & $\begin{array}{l}\text { Production } \\
\text { (million tons) }\end{array}$ \\
\hline Beijing & 0.02 & 0.12 & 0.00 & 0.00 & 0.09 & 0.50 \\
\hline Tianjin & 0.11 & 0.59 & 0.02 & 0.12 & 0.20 & 1.01 \\
\hline Hebei & 2.34 & 14.30 & 0.08 & 0.54 & 3.17 & 16.71 \\
\hline Shanxi & 0.67 & 2.59 & 0.00 & 0.01 & 1.68 & 9.38 \\
\hline Inner Mongolia & 0.56 & 1.53 & 0.08 & 0.52 & 3.37 & 21.86 \\
\hline Liaoning & 0.01 & 0.03 & 0.56 & 4.52 & 2.33 & 11.71 \\
\hline Jilin & 0.00 & 0.00 & 0.75 & 5.88 & 3.70 & 27.34 \\
\hline Heilongjiang & 0.15 & 0.47 & 3.21 & 22.51 & 5.44 & 33.43 \\
\hline Shanghai & 0.04 & 0.19 & 0.10 & 0.84 & 0.00 & 0.03 \\
\hline Jiangsu & 2.16 & 11.60 & 2.27 & 19.12 & 0.44 & 2.39 \\
\hline Zhejiang & 0.08 & 0.31 & 0.82 & 5.90 & 0.07 & 0.30 \\
\hline Anhui & 2.43 & 13.94 & 2.22 & 13.95 & 0.85 & 4.66 \\
\hline Fujian & 0.00 & 0.01 & 0.80 & 4.97 & 0.05 & 0.20 \\
\hline Jiangxi & 0.01 & 0.03 & 3.34 & 20.25 & 0.03 & 0.12 \\
\hline Shandong & 3.74 & 22.64 & 0.12 & 1.01 & 3.13 & 19.88 \\
\hline Henan & 5.41 & 33.29 & 0.65 & 5.29 & 3.28 & 17.32 \\
\hline Hubei & 1.07 & 4.22 & 2.14 & 17.29 & 0.64 & 2.94 \\
\hline Hunan & 0.03 & 0.10 & 4.12 & 26.34 & 0.35 & 1.89 \\
\hline Guangdong & 0.00 & 0.00 & 1.89 & 10.92 & 0.18 & 0.77 \\
\hline Guangxi & 0.00 & 0.00 & 2.03 & 11.66 & 0.58 & 2.66 \\
\hline Hainan & 0.00 & 0.00 & 0.31 & 1.55 & 0.00 & 0.00 \\
\hline Chongqing & 0.09 & 0.27 & 0.69 & 5.03 & 0.47 & 2.56 \\
\hline Sichuan & 1.17 & 4.23 & 1.99 & 15.27 & 1.38 & 7.52 \\
\hline Guizhou & 0.25 & 0.62 & 0.68 & 4.03 & 0.79 & 3.14 \\
\hline Yunnan & 0.43 & 0.84 & 1.14 & 6.66 & 1.53 & 7.43 \\
\hline Xizang (Tibet) & 0.04 & 0.24 & 0.00 & 0.00 & 0.00 & 0.02 \\
\hline Shaanxi & 1.08 & 4.17 & 0.12 & 0.91 & 1.15 & 5.40 \\
\hline Gansu & 0.79 & 2.72 & 0.01 & 0.04 & 1.00 & 5.64 \\
\hline Qinghai & 0.09 & 0.35 & 0.00 & 0.00 & 0.03 & 0.19 \\
\hline Ningxia & 0.13 & 0.41 & 0.08 & 0.62 & 0.29 & 2.24 \\
\hline Xinjiang & 1.14 & 6.42 & 0.08 & 0.76 & 0.91 & 6.41 \\
\hline
\end{tabular}

$$
X_{t}=\frac{\sum_{i=1}^{n}\left(P_{i, t} \times X_{i}\right)}{\sum_{i=1}^{n} P_{i, t}} ; Y_{t}=\frac{\sum_{i=1}^{n}\left(P_{i, t} \times Y_{i}\right)}{\sum_{i=1}^{n} P_{i, t}}
$$

$X_{i}$ and $Y_{i}$ are the longitude and latitude of the geographical centroid of province $i$; $P_{i, t}$ represents the three major crop area or production for year $t$ in province $i$; $t$ covers the period from 1949 to 2014; and $n$ is the total number of crop-producing provinces $(n=31)$. The centroids for years $k$ and $k+m$ were set as $P_{k}\left(x_{k}, y_{k}\right)$ and $P_{k+m}\left(x_{k+m}, y_{k+m}\right)$; thus, the direction 
model of the centroid moving from $P_{k}$ to $P_{k+m}$ was as follows:

$$
\theta=\arctan \frac{y_{k+m}-y_{k}}{x_{k+m}-x_{k}}
$$

The distance model of centroids moving from $P_{k}$ to $P_{k+m}$ was as follows:

$$
d_{m}=\sqrt{\left(x_{k+m}-x_{k}\right)^{2}+\left(y_{k+m}-y_{m}\right)^{2}}
$$

\section{Results}

\subsection{Relocation of the rice area and production}

We quantified the movement of the geographical centroids for the area and production of rice in Figure 1. The result showed a distinct north-eastward movement from 1949 to 2014. The major planting region for rice production was in Hunan province in 1949, while the geographical centroids of the rice area and production in China were $112.47^{\circ} \mathrm{E} / 28.15^{\circ} \mathrm{N}$ and $111.50^{\circ} \mathrm{E} / 28.51^{\circ} \mathrm{N}$, respectively. By 2014 , the centroids of the rice area had moved 413.39 $\mathrm{km}$ in the $34.32^{\circ}$ northeasterly (latitude $3.08^{\circ} \mathrm{N}$, longitude $2.1^{\circ} \mathrm{E}$ ) direction at a speed of 6.36 $\mathrm{km} /$ year from central Hunan into Hubei province. The rice area centroids moved $156.81 \mathrm{~km}$ north at the fastest speed of $11.20 \mathrm{~km} /$ year from 2000 to 2014 and $104.79 \mathrm{~km}$ northeast with a speed of $10.48 \mathrm{~km} /$ year from 1990 to 2000 . In addition, the rice production centroids moved $509.26 \mathrm{~km}$ towards the $44^{\circ}$ northeasterly (latitude $3.22^{\circ} \mathrm{N}$, longitude $3.27^{\circ} \mathrm{E}$ ) direction at a speed of $7.83 \mathrm{~km} /$ year from central Hunan into Henan province between 1949 and 2014. The rice production centroids moved $150.84 \mathrm{~km}$ north at the fastest speed of 13.71 $\mathrm{km} /$ year from 1949 to 1960 ; however, they moved the longest distance of $175.54 \mathrm{~km}$ northeast at the second fastest speed of $12.54 \mathrm{~km} /$ year from 2000 to 2014 (Table 2).
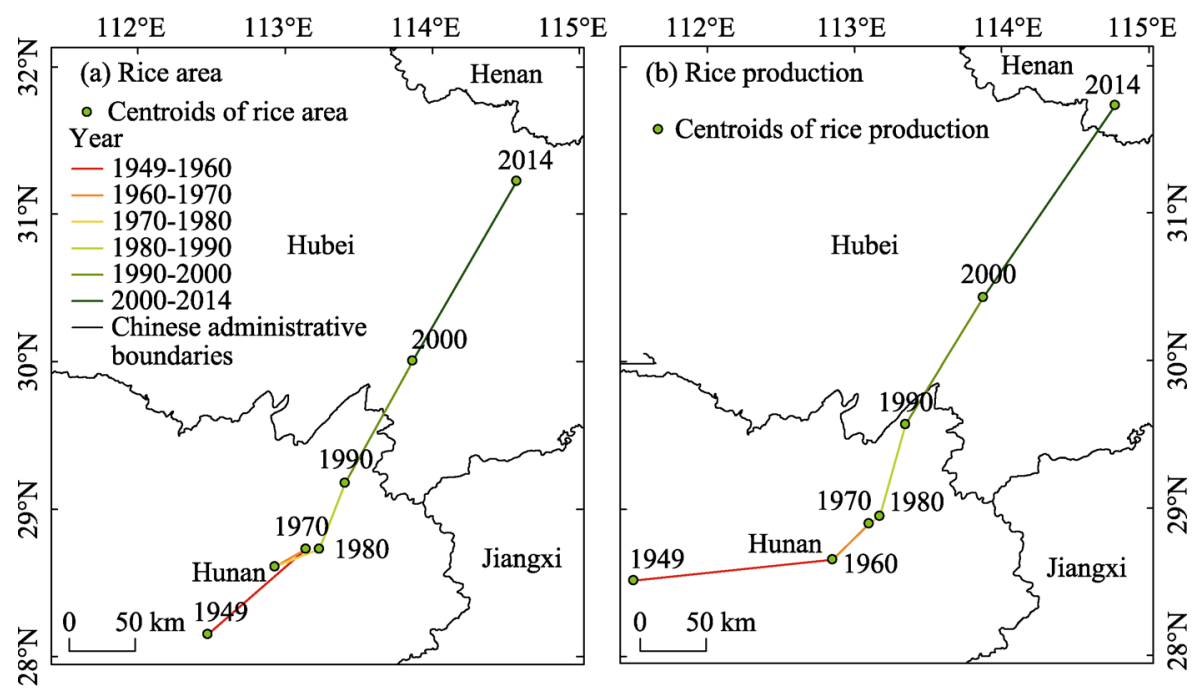

Figure 1 Movements of the geographical centroids for rice area and production between 1949 and 2014

\subsection{Relocation of the maize area and production}

Maize area and production increased at annual speeds of 0.37 million ha and 3.12 million 


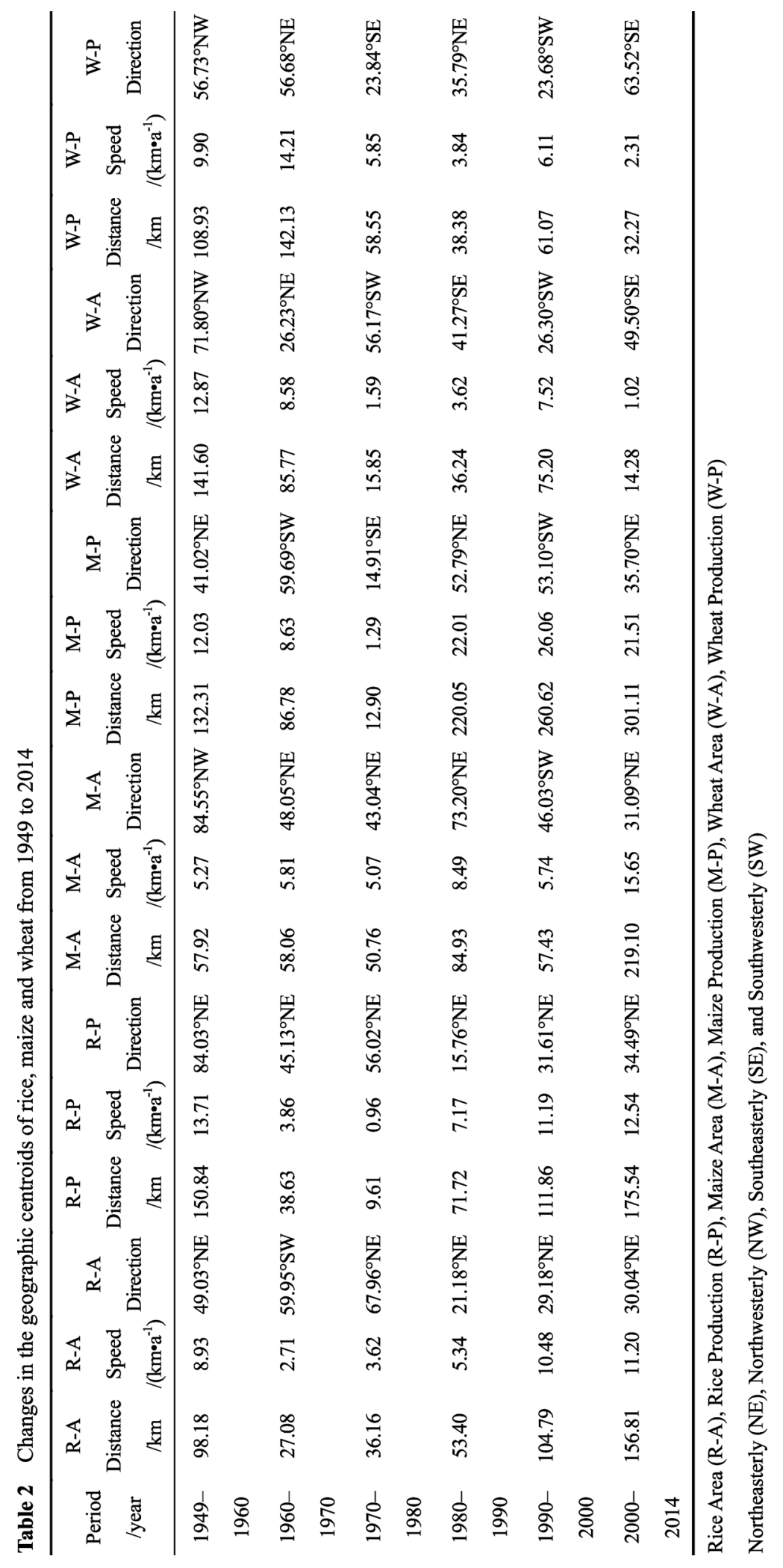


tons from 1949 to 2014. We also quantified the movement of the geographical centroids for the maize area and production over the last six decades, as shown in Figure 2. Both figures showed that the maize planting hot zones moved from the northern part of Henan province to the central part of Hebei province. The geographical centroids of the maize area and production in China moved $307.15 \mathrm{~km}$ in the $34.33^{\circ}$ northeasterly (latitude $2.29^{\circ} \mathrm{N}$, longitude $1.56^{\circ} \mathrm{E}$ ) direction and $308.16 \mathrm{~km}$ in $30.79^{\circ}$ northeasterly (latitude $2.39^{\circ} \mathrm{N}$, longitude $1.42^{\circ} \mathrm{E}$ ) direction, respectively. The geographical centroids of the maize area showed a distinct northeast movement at the longest distance of $219.10 \mathrm{~km}$ and the fastest speed of 15.65 $\mathrm{km} /$ year between 2000 and 2014. Notably, the centroids of the maize area showed a similar speed before 2000. In contrast, the geographical centroids of maize production did not display a consistent direction every year and engaged in a more random movement than the centroids of maize area. However, the data still showed a northeastern movement over the last six decades. Clearly, most of the centroids for maize production were distributed in Hebei province, and some were located along the border of Henan and Hebei provinces. The geographical centroids of maize production in 1949 were located in the southern part of Hebei province but moved to Henan province in 1959 and then to the middle of Hebei province in 1960; most of the centroids were subsequently distributed within Hebei province from 1960 to 2014. The geographical centroids of maize production moved $260.62 \mathrm{~km}$ in the $53.10^{\circ}$ southwesterly direction at the fastest speed of $26.06 \mathrm{~km} /$ year between 1990 and 2000 , then moved the longest distance of $301.11 \mathrm{~km}$ in the $35.70^{\circ}$ northeasterly direction at a speed of $21.51 \mathrm{~km} /$ year.
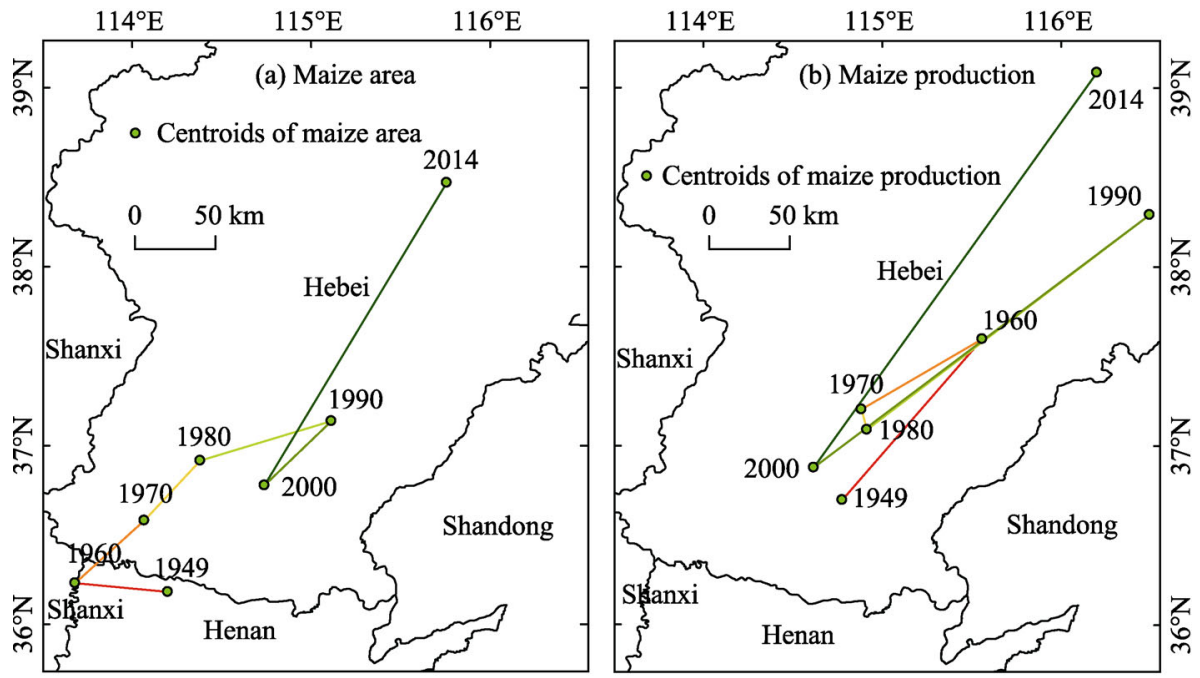

Figure 2 Movements in the geographical centroids of the maize area and production between 1949 and 2014 (Legend of lines is shown in Figure 1a)

\subsection{Relocation of the wheat area and production}

(1) Wheat

The dynamic trend in the geographical centroids of the wheat area and production, which were distributed randomly along the border of Henan and Shanxi provinces, completely differed from those of the other two crops. The complete trajectories did not show regular 
movement over the last six decades and instead returned to Henan. For example, the geographical centroids of wheat area moved in the direction of $71.8^{\circ}$ northwesterly with both the longest distance of $141.60 \mathrm{~km}$ and the fastest speed of $12.87 \mathrm{~km} /$ year across Henan and Shanxi provinces from 1949 to 1960 . However, they moved $14.28 \mathrm{~km}$ at $49.50^{\circ}$ southeasterly at the slowest speed of $1.02 \mathrm{~km} /$ year, keeping to Henan province from 2000 to 2014 . From 1960 to 1990 , nearly all of the wheat area centroids were scattered within Shanxi province and moved towards different directions at an average speed of $4.60 \mathrm{~km} / \mathrm{year}$. As expected, the geographical centroids of wheat production did not display a linear movement trend over the last six decades (Figure $3 b$ ). Unlike the area, the production centroids exhibited consistent movement in a longitudinal direction but moved randomly in the latitudinal direction, moving $90.23 \mathrm{~km}$ in the direction of $60.02^{\circ}$ northeasterly (latitude $0.41^{\circ} \mathrm{N}$, longitude $0.7^{\circ} \mathrm{E}$ ) between 1949 and 2014. The production centroids showed a distinct northeastern movement at the longest distance of $142.13 \mathrm{~km}$ and the fastest speed of $14.21 \mathrm{~km} / \mathrm{year}$ between 1960 and 1970. To some extent, the relatively concentrated areas of wheat production centroids were located in a more eastern direction than the wheat area centroids.
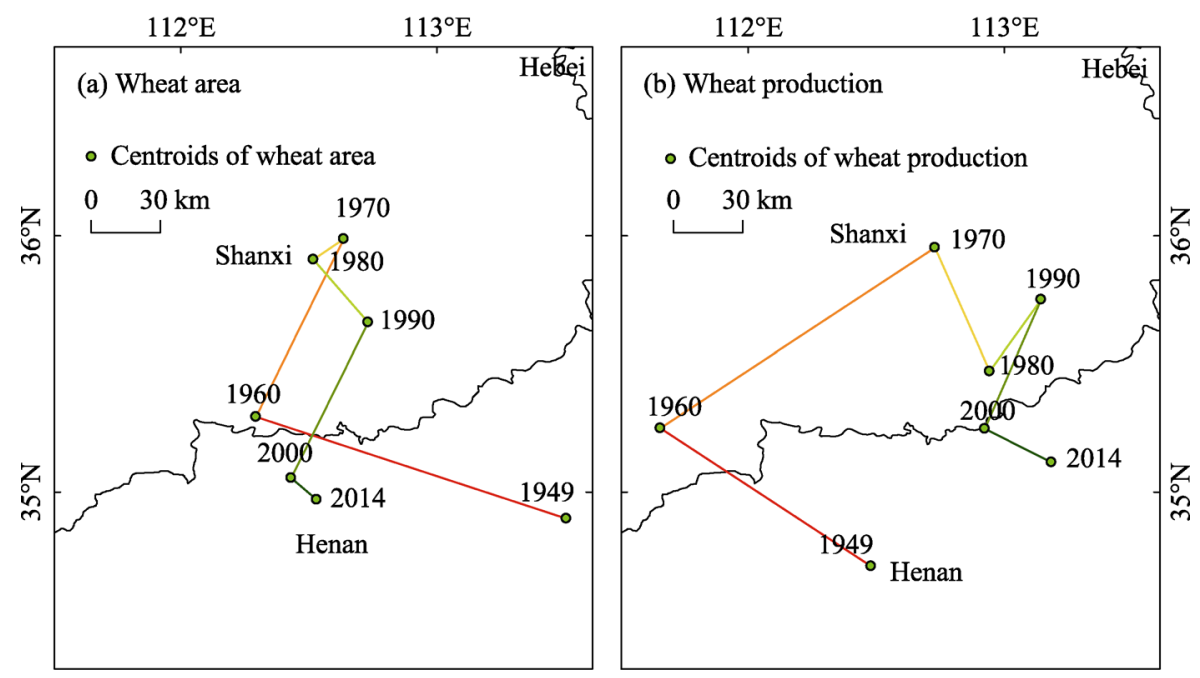

Figure 3 Movements of the geographical centroids for the total wheat area and production between 1949 and 2014 (Legend of lines is shown in Figure 1a)

(2) Spring wheat

Spring wheat is primarily distributed north of the Great Wall in China. We quantified the geographical centroid movement of the spring wheat area and production as shown in Figure 4. Nearly all of the area centroids were distributed within Inner Mongolia, but moved from the central to the eastern areas between 1957 and 1980 and then from the eastern to the western areas between 1980 and 2014. There was no spring wheat planting in the missing years. In general, the area centroid moved $597.18 \mathrm{~km}$ in the direction of $86.79^{\circ}$ southwesterly (latitude $0.41^{\circ} \mathrm{N}$, longitude $7.22^{\circ} \mathrm{E}$ ) from 1957 to 2014 , which showed distinct movement in longitude but not in latitude. The production centroids and migration tendency maintained a similar movement as the area but traversed a longer distance, moving 710.40 $\mathrm{km}$ in the direction of $86.65^{\circ}$ southwesterly (latitude $0.50^{\circ} \mathrm{N}$, longitude $8.53^{\circ} \mathrm{E}$ ) from 1957 to 2014. 

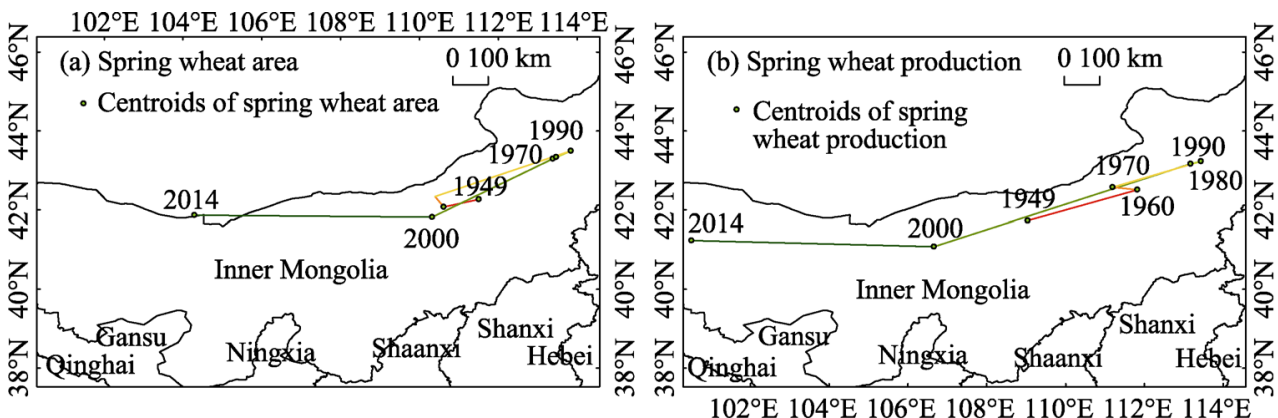

Figure 4 Movements of the geographical centroids for the spring wheat area and production between 1949 and 2014 (Legend of lines is shown in Figure 1a)

(3) Winter wheat

Winter wheat is primarily distributed south of the Great Wall in China. The planting area of winter wheat was approximately 20 million ha in 2003, accounting for 90 percent of the total wheat area. This explains the similar geographical centroids of winter wheat and total wheat. We also quantified the geographical centroids of the winter wheat area and production in Figure 5 (a, Winter Wheat Area; b, Winter Wheat Production). The geographical centroid of the winter wheat area moved $63.71 \mathrm{~km}$ towards $47.97^{\circ}$ southwesterly (latitude $0.38^{\circ} \mathrm{N}$, longitude $0.43^{\circ} \mathrm{E}$ ) between 1949 and 2014 . With the exception of the $1960 \mathrm{~s}$, the majority of area centroids were distributed in Henan province, concentrated in the northern part of Henan. Unlike the geographical centroids for winter wheat area, the production was more scattered in Henan and Shanxi provinces than that for the winter wheat area over the last six decades. The geographical centroids of winter wheat production moved $150.31 \mathrm{~km}$ towards $86.01^{\circ}$ northeasterly (latitude $0.09^{\circ} \mathrm{N}$, longitude $1.35^{\circ} \mathrm{E}$ ) from 1949 to 2014 , which showed distinct movement in longitude but not in latitude. Like the area centroids, the production centroids were primarily distributed in Shanxi province during the 1960s and in Henan province during other time periods.
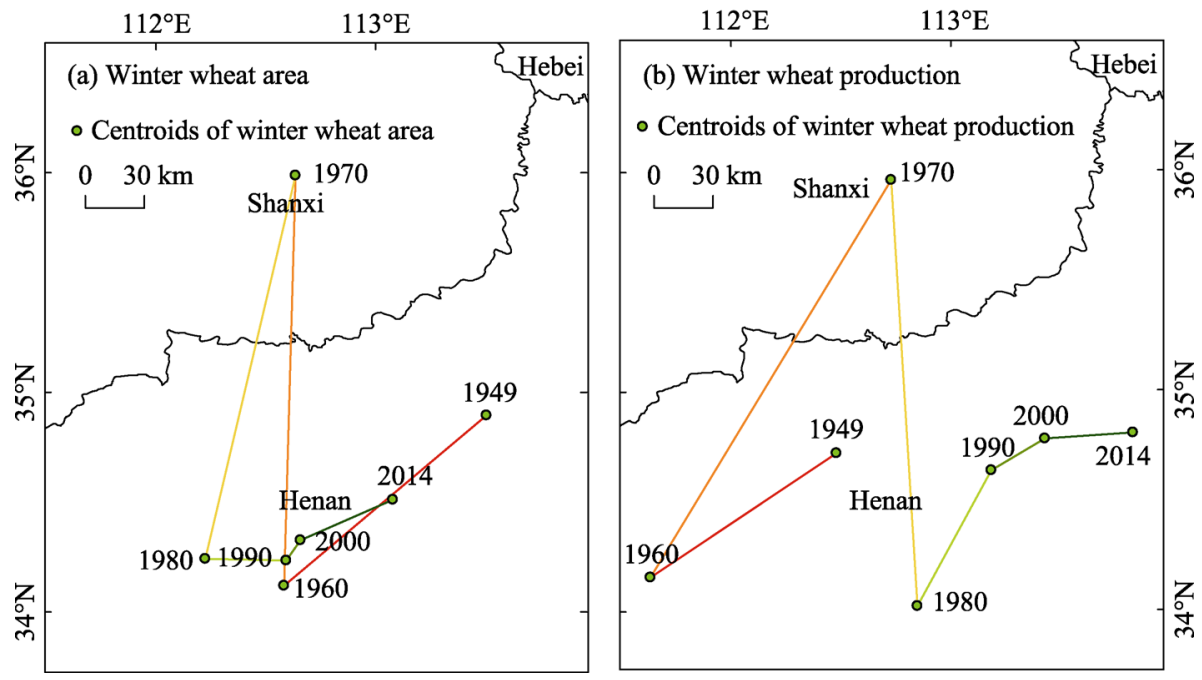

Figure 5 Movements in the geographical centroids of the winter wheat area and production between 1949 and 2014 (Legend of lines is shown in Figure 1a) 


\section{Discussion}

(1) Regional heterogeneity in the natural environment and the socio-economy of different districts has shaped the spatial distribution of crop production in each province. In terms of area, maize planting area significantly increased in Northeast China during the last six decades, which moved the centroids of the maize area a long distance to the northeast. Additionally, the increased maize planting area in Northeast China has contributed to the total planting area in China. Many studies have shown that there is a close relationship between the climate factors and the maize distribution, and the northeast's maize cultivation is inordinately affected due to its sensitivity to climate change (Zhao et al., 2015; He et al., 2016; Liu et al., 2017). Rice planting area also extended dramatically towards Northeast China, as rice is now grown as far as the northern border of Heilongjiang province due to higher temperatures. During the same time period, the rice area in southern China has decreased due to shifting economic patterns, reduced agricultural land use and increased land use efficiency. These two opposite phenomena experienced by such sensitive rice areas have conspicuously propelled the centroids of the rice area to the northeast. The rice area result is consistent with previous studies in which the centroid of Chinese rice shifted northeast for a long distance over the last few decades (Liu et al., 2013; Li et al., 2015). Unlike maize and rice, the centroids of wheat area did not show a distinct direction at a provincial scale but were randomly distributed between Shanxi and Henan provinces during this period. This phenomenon could be explained by the spatial characteristics of wheat distribution in which a consecutive increasing trend in the wheat planting area was only found in North China but not in the other regions. Therefore, we observed a series of wheat centroids moving irregularly on both sides of the border between Henan and Shanxi provinces, with uncertain directions and distances every ten years. The spatial distribution of wheat was circumscribed by both climate and human factors. It is largely due to the warming temperatures in mid and high latitudes that pushed the northern boundary of wheat to extend to north before the 1980s, but the significant improvement of wheat irrigation technology in North China and the productive benefit of wheat played a major role to move the key region to the south after the 1980s. (Sun et al., 2012; Wang et al., 2012; Liu et al., 2016).

(2) Similar to the area, the centroids of crop production also showed distinct regional movements during this period. Rice and maize production experienced dramatic increases in Northeast and North China due to the improvements in production management and innovation in crop varieties. The rapid development of irrigation facilities and the use of large amounts of chemical fertilizers also significantly contributed to the changes in the geographical centroids related to cultivation. Additionally, the Household Responsibility System (HRS) was another important reason for spatial changes in crop planting production. The HRS significantly stimulated production enthusiasm in farmers and contributed to the geographical movements of crop cultivation during its gradual integration in China after 1984. Under the HRS, farmers could decide what to plant and how to manage their crop system according to their understanding of the hydrothermal conditions and nutrient requirements of crops grown in Northeast China. This ultimately led to an increased production of rice which propelled rice production centroids a long distance to the northeast (Li et al., 2015). However, the hot spots of the rice planting region were distributed in both Northeast China and South China, while maize was distributed in North China. Both crops showed distinct 
movements within their primary areas of production. As noted previously, wheat is primarily produced south of the Great Wall, and winter wheat in North China accounting for a large proportion of the total wheat. Thus, the wheat production centroids showed no predictable pattern. Increasingly, innovative technologies and improved management practices in different regions have been applied appropriately to improve the wheat production and famer's profit, enabling the location of wheat production to change significantly at the national scale (Xu et al., 2013; You et al., 2009).

(3) Our study has shown the spatio-temporal changes of the geographical centroids of three main crops area and production (rice, maize and wheat) in China from 1949 to 2014, showing the geographical centroids of each crop had unique migration characteristics from one to another. The geographical centroids of rice and maize exhibited an obvious northeastward movement while wheat showed no directional movement at the national scale during this period. Significant changes in these crops' centroids movement trends are unlikely to be detected during short time frames as shifts in climate and social conditions affect agriculture at larger time scales (i.e. decades). The migration of the crops' centroids over long periods reflects the use of agricultural production resources within the scope of human agricultural production and is the basis for understanding the adjustment and optimization of crop planting structure. Hence, this dynamic change in the spatial distribution of crops should be taken into account in order to plan crop planting management objectively and design adaptation strategies purposively. Rapid urbanization (particularly in the south), technical development, widened crop comparison gains, land use policy changes, agricultural mechanization, varieties of conversion, and climate change have significantly influenced crop distribution extension and location region, so the future research is needed to study the driving mechanisms between the crops spatio-temporal distribution and changes of the external factors mentioned above, in order to improve the understanding of the self-adjustment capacity in cropping system and its response to external factors.

\section{Conclusions}

This study applied the crop centroids model; acquired the geographical centroids of Chinese crop planting area and production during 1949 to 2014 of rice, maize, wheat, winter and spring wheat; and analysed the geographical dynamics of the crop planting area and production. The conclusions are as follows:

(1) During the last six decades, the centroids of the rice and maize areas showed distinct northeast movements. The geographical centroid of the rice area moved $396.27 \mathrm{~km}$ in the direction of $34.32^{\circ}$ northeasterly (latitude $3.08^{\circ} \mathrm{N}$, longitude $2.1^{\circ} \mathrm{E}$ ) at a speed of $6.1 \mathrm{~km} /$ year from central Hunan province into Hubei province, while maize moved $288.6 \mathrm{~km}$ in the direction of $34.33^{\circ}$ northeasterly (latitude $2.29^{\circ} \mathrm{N}$, longitude $1.56^{\circ} \mathrm{E}$ ). However, the wheat showed a more irregular movement pattern due to its specific planting distribution characteristics in China, as did the winter and spring wheat.

(2) In terms of the spatial and temporal movements of crop planting production centroids, the centroids of rice production moved $475.08 \mathrm{~km}$ in the direction of $45.44^{\circ}$ northeasterly (latitude $3.22^{\circ} \mathrm{N}$, longitude $3.27^{\circ} \mathrm{E}$ ) at a speed of $7.31 \mathrm{~km} /$ year from central Hunan into Henan province. The maize production centroids were not regular for every year and displayed a more random movement than the centroids of the maize area; however, they eventually 
showed a northeast movement trend over the last six decades. The wheat production was similar to the wheat area in that there was no distinct directional consistency, and changes in the specific region have unique distribution characteristics.

(3) The centroid migration trajectory of each crop's area and production exhibits different degrees of inconsistency which suggests that the changing amplitude and rate of each crops' yield are not the same between different regions in China. The adoption of modern varieties, developing technology, increased use of fertilizers and climate change in the past decades have dramatically increased crop yields in China, but these resources and technologies varied from a region to another because of different natural conditions and technical levels. The inconsistencies in direction and distance of crop area and production centroids reflect the spatial variation caused by regional disparities in agricultural investment, field management, and natural conditions.

\section{References}

Carter C A, Chen J, Chu B., 2003. Agricultural productivity growth in China: Farm level versus aggregate measurement. China Economic Review, 14(1): 53-71.

Cohn A S, VanWey L K, Spera S A et al., 2016. Cropping frequency and area response to climate variability can exceed yield response. Natural Climate Change, 6(6): 601-604.

Cui Z, Wu L, Ye Y et al., 2014. Trade-offs between high yields and greenhouse gas emissions in irrigation wheat cropland in China. Biogeosciences, 11(8): 2287-2294.

Deb P, Shrestha S, Babel M S, 2015. Forecasting climate change impacts and evaluation of adaptation options for maize cropping in the hilly terrain of Himalayas: Sikkim, India. Theoretical and Applied Climatology, 121(3/4): 649-667.

Ding J, Huang J, Jia X et al., 2015. Direct farm, production base, traceability and food safety in China. Journal of Integrative Agriculture, 14(11): 2380-2390.

He C, Liu Z, Xu M et al., 2017. Urban expansion brought stress to food security in China: Evidence from decreased cropland net primary productivity. Science of the Total Environment, 576: 660-670.

He Q, Zhou G, 2016. Climate-associated distribution of summer maize in China from 1961 to 2010. Agriculture Ecosystems and Environment, 232: 326-335.

Iizumi T, Ramankutty N, 2015. How do weather and climate influence cropping area and intensity? Global Food Security, 4: 46-50.

Kuemmerle T., Erb K., Meyfroidt P et al., 2013. Challenges and opportunities in mapping land use intensity globally. Current Opinion in Environmental Sustainability, 5(5): 484-493.

Li K, Yang X, Mu C et al., 2013. The possible effects of global warming on cropping systems in China (VIII: The effects of climate change on planting boundaries of different winter-spring varieties of winter wheat in China. Scientia Agricultura Sinica, 46(8): 1583-1594. (in Chinese)

Li Z, Liu Z, Anderson W et al., 2015. Chinese rice production area adaptations to climate changes, 1949-2010. Environmental Science and Technology, 49(4): 2032-2037.

Li Z, Yang P, Tang H et al., 2014. Response of maize phenology to climate warming in Northeast China between 1990 and 2012. Regional Environmental Change, 14(1): 39-48.

Liu T, Zhou G, Tan K et al., 2016. Review on research of irrigation regime and its environmental effect in winter wheat field of North China Plain. Acta Ecologica Sinica, 36(19): 5979-5986. (in Chinese)

Liu Y, Qin Y, Ge Q et al., 2017. Reponses and sensitivities of maize phenology to climate change from 1981 to 2009 in Henan Province, China. Journal of Geographical Sciences, 27(9): 1072-1084.

Liu Z, Li Z, Tang P et al., 2013. Change analysis of rice area and production in China during the past three decades. Journal of Geographical Sciences, 23(6): 1005-1018.

Liu Z, Yang P, Tang H et al., 2015. Shifts in the extent and location of rice cropping areas match the climate 
change pattern in China during 1980-2010. Regional Environmental Change, 15(5): 919-929.

Nelson E, Sander H, Hawthorne P et al., 2010. Projecting global land-use change and its effect on ecosystem service provision and biodiversity with simple models. Plos One, 5(12): e14327-e14327.

Sun J, Zhou G, Sui X, 2012. Climatic suitability of the distribution of the winter wheat cultivation zone in China. European Journal of Agronomy, 43(3): 77-86.

Szumigalski A, Acker R V, 2016. Weed suppression and crop production in annual intercrops. Weed Science, 53(6): 813-825.

Tan J, Yang P, Liu Z et al., 2014. Spatio-temporal dynamics of maize cropping system in Northeast China between 1980 and 2010 by using spatial production allocation model. Journal of Geographical Sciences, 24(3): 397-410.

Verburg P H, Mertz O, Erb K H et al., 2013. Land system change and food security: Towards multi-scale land system solutions. Current Opinion in Environmental Sustainability, 5(5): 494-502.

Wang P, Zhang J, Xie D et al., 2012. Spatial characteristic analysis on planting area of winter wheat in China from 1961 to 2010. Journal of Natural Resources, 27(2): 215-224. (in Chinese)

$\mathrm{Wu}$ W, Verburg P H, Tang H, 2014. Climate change and the food production system: Impacts and adaptation in China. Regional Environmental Change, 14(1): 1-5.

Xia T, Wu W, Zhou Q et al., 2016. Model-based analysis of spatio-temporal changes in land use in Northeast China. Journal of Geographical Sciences, 26(2): 171-187.

$\mathrm{Xu} \mathrm{Z,} \mathrm{Yu} \mathrm{Z,} \mathrm{Zhao} \mathrm{J,} \mathrm{2013.} \mathrm{Theory} \mathrm{and} \mathrm{application} \mathrm{for} \mathrm{the} \mathrm{promotion} \mathrm{of} \mathrm{wheat} \mathrm{production} \mathrm{in} \mathrm{China:} \mathrm{Past,} \mathrm{present}$ and future. Journal of the Science of Food and Agriculture, 93(10): 2339.

Yin X, Jabloun M, Olesen J E et al., 2016. Effects of climatic factors, drought risk and irrigation requirement on maize yield in the Northeast Farming Region of China. Journal of Agricultural Science, firstview(7): 1-19.

You L, Markw R, Stanley W et al., 2009. Impact of growing season temperature on wheat productivity in China. Agricultural and Forest Meteorology, 149(6/7): 1009-1014.

You L, Wood S, 2006. An entropy approach to spatial disaggregation of agricultural production. Agricultural Systems, 90(1-3): 329-347.

You L, Wood S, Wood-Sichra U., 2009. Generating plausible crop distribution maps for Sub-Saharan Africa using a spatially disaggregated data fusion and optimization approach. Agricultural Systems, 99(2/3): 126-140.

Zhang L, Wu W, Yang P et al., 2013. Temporal and spatial changes in crop patterns of Binxian County in Heilongjiang Province. Scientia Agricultura Sinica, 46(15): 3227-3237. (in Chinese)

Zhao J, Guo J, 2013. Possible trajectories of agricultural cropping systems in China from 2011 to 2050. American Journal of Climate Change, 2(3): 191-197.

Zhao J, Guo J, Xu Y et al., 2015. Effects of climate change on cultivation patterns of spring maize and its climatic suitability in Northeast China. Agriculture Ecosystems and Environment, 202: 178-187.

Zheng C, Guo J, Zhao J, 2017. Impacts of future climate change on agroclimatic resources in Northeast China. Journal of Geographical Sciences, 27(9): 1044-1058. 